Article

\title{
Nanomechanical Properties of Articular Cartilage Due to the PRP Injection in Experimental Osteoarthritis in Rabbits
}

\author{
Mikhail Ihnatouski ${ }^{1}$, Jolanta Pauk ${ }^{2, * \mathbb{D}}$, Boris Karev ${ }^{3}$ and Dmitrij Karev ${ }^{4}$ \\ 1 Scientific and Research Department, Yanka Kupala State University of Grodno, Grodno, Ozheshko str., \\ 22, 230023 Grodno, Belarus; mii_by@mail.ru \\ 2 Mechanical Engineering Department, Bialystok University of Technology, Biomedical Engineering Institute, \\ Wiejska 45A, 15-351 Bialystok, Poland \\ 3 Department of Orthopedic and Traumatology, Grodno City Emergency Hospital, Sovietskih Pogranichnikov \\ str., 115, 230027 Grodno, Belarus; bkarev@gmail.com \\ 4 Department of Traumatology, Orthopedics and Field Surgery, Grodno State Medical University, Gorkogo str. \\ 80, 230009 Grodno, Belarus; dmitriy.karev@gmail.com \\ * Correspondence: j.pauk@pb.edu.pl
}

Academic Editors: Maria Rosaria Plutino, Sebania Libertino and Giuseppe Rosace Received: 17 July 2020; Accepted: 14 August 2020; Published: 15 August 2020

\begin{abstract}
The purpose of this study was twofold. Firstly, we proposed a measurement protocol for the atomic force microscopy (AFM) method to determine the nanomechanical properties of articular cartilage in experimental osteoarthritis in rabbits. Then, we verified if mechanical properties can be evaluated with AFM shortly after platelet-rich plasma (PRP) injection. We hypothesized that the modulus determined by AFM indentation experiments could be utilized as a progressive disease marker during the treatment of osteoarthritis. The rabbits were equally divided into three groups of six: control (group 1); injections of saline $(0.5 \mathrm{~mL})$ and $10 \%$ surgical talc (Talcum Pharmaceutical ${ }^{\circledR}$, Minsk, Belarus) were delivered into the right knee under the patella (group 2 and 3); and PRP was injected into the right knee (group 3). In group 2, the arithmetic average of absolute values (Ra) change was a $25 \%$ increase; the maximum peak height (Rp) increased by over $102 \%$, while the mean spacing between local peaks (S) increased by $28 \%(p<0.05)$. In group 3, Ra increased by $14 \%$ and $\mathrm{Rp}$ increased by $32 \%$, while S decreased by $75 \%(p<0.05)$. The Young's modulus of the surface layers decreased by $18 \%$ as a result of induced model of osteoarthritis (IMO) $(p<0.05)$, and it increased by $9 \%(p<0.05)$ as a result of PRP therapy, which means that the mechanical properties of cartilage were partially recovered. This research demonstrates that Young's modulus utilized on a nanometer scale has potential to be a progressive disease marker during the treatment of osteoarthritis.
\end{abstract}

Keywords: hyaline cartilage; platelet-rich plasma therapy; induced model; osteoarthritis; atomic force microscopy

\section{Introduction}

Osteoarthritis $(\mathrm{OA})$ is a musculoskeletal disease common throughout the world, affecting $10-15 \%$ of the population aged 45 years and older [1,2]; over 30 million people in the United States [3] and 302 million worldwide suffer from OA [4]. Currently, the disease ranks 12th globally among all the causes of disability in the population [4]. The prevalence of osteoarthritis is increasing, and it is expected that 78 million adults in the US will have been affected by 2040 [5]. It is a chronic progressive disease whose causes include imbalances between anabolic and catabolic processes in joint tissues [6]. The risk factors include old age, obesity, and type 2 diabetes mellitus, previous damage, or mechanical overload to the joint [7]. Hyaline cartilage undergoes degenerative-dystrophic changes 
with subsequent involvement of the subchondral bone [8,9]. Moreover, chronic synovitis, sclerosis of the joint capsule, meniscal degeneration, and articular and muscular atrophy are also observed. Osteoarthritis is indicated as one of the most common forms of arthritis, with the knee joint being the most commonly affected site [6,7,10-12].

Preclinically, the pathogenesis, pathophysiology, and the effect of therapeutic intervention in OA treatment require the development of animal models, which play a crucial role in the understanding of the disease. Such models are classified in literature based on their etiology, i.e., as primary osteoarthritis, post-traumatic osteoarthritis, etc. [12]. Both small (mouse, rat, rabbit, and guinea pig) and large animals (dog, goat/sheep, and horse) have been used to develop OA models [12-16]. Chemically induced models are mainly used for the assessment of the effectiveness of treatment in inflammation. They involve the injection of an inflammatory compound (sodium monoiodoacetate, quinolone, collagenase, etc.) directly into the knee joint to induce OA in animals [12]. Studies of histopathological outcomes have been widely published in [15]; however, the mechanical properties and the submicron surface morphology of animal hyaline cartilage remain unclear.

In the 21st century, orthopedists' attention turned to conservative methods of joint disease treatment, indicating that new modalities should focus on multifunctional treatment and solving a set of biotribological problems [16,17]. Several treatment options were used to stop the progression of inflammation. These include conservative methods, non-steroidal anti-inflammatory drugs, glucocorticosteroids, and hyaluronic acid, as well as therapeutic exercise and assistive devices [16]. Current studies involve the use of platelet-rich plasma therapy (PRP) in the treatment of osteoarthritis because it is easy to prepare and well-tolerated. Some basic, preclinical, and clinical case studies report the ability of platelet-rich plasma to improve musculoskeletal conditions, including osteoarthritis [12,16,18-24]. Nevertheless, there are still concerns regarding its clinical efficiency, mainly due to the heterogeneity of the used methods and the obtained results, lack of standardization, and quantification of the PRP protocols [25-31]. Defining additional parameters related to articular cartilage properties is desirable.

Despite the numerous advantages of available imaging modalities, their limitations are in ultrastructural details at molecular resolution, the complexity of sample preparation procedures, and the lack of the morphological distortion of cells at nanometer resolution [32-35]. Osteoarthritis appears as a result of changes in elasticity of cells and tissues; hence, it is crucial to consider aspects such as the mechanical properties and the submicron surface morphology of hyaline cartilage. Lately, atomic force microscopy was recognized as a powerful tool to assess the properties of articular cartilage [9,36-44]. Therefore, the purpose of this study was twofold. Firstly, we proposed a measurement protocol for the AFM method to determine the nanomechanical properties of articular cartilage in experimental osteoarthritis in rabbits. Then, we verified if mechanical properties can be evaluated with AFM shortly after PRP injection. We hypothesized that modulus determined by AFM indentation experiments could be utilized as a progressive disease marker during the treatment of osteoarthritis.

\section{Results}

Within several minutes following the injection, all the animals were conscious and started to move. None of the rabbits showed any sign of a knee infection or swelling or died during the test. From the first day, rabbits developed synovitis, manifested as an increase in the local temperature and the diameter of the joint. Two independent surgeons, without prior knowledge of the experimental groups, performed the observation.

\subsection{Histologic Findings according to the Non-Treated and PRP-Injected Knees}

The difference of histologic scores in group 3 was higher (3.3 (1.4)) than those in group $2(2.1$ (1.8)), $p<0.05$. Histologic examination showed nearly normal cartilage surfaces with normal cellularity in the transitional and radial zones in group 3 with PRP injection. 
2.2. Submicron Surface Morphology of Rabbits Cartilage and the Mechanical Properties of Rabbits

AFM images in the three groups were conducted in contact mode in the three groups (Figure 1).

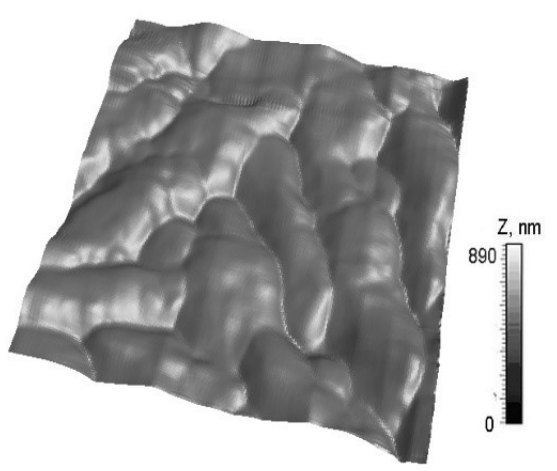

(a)

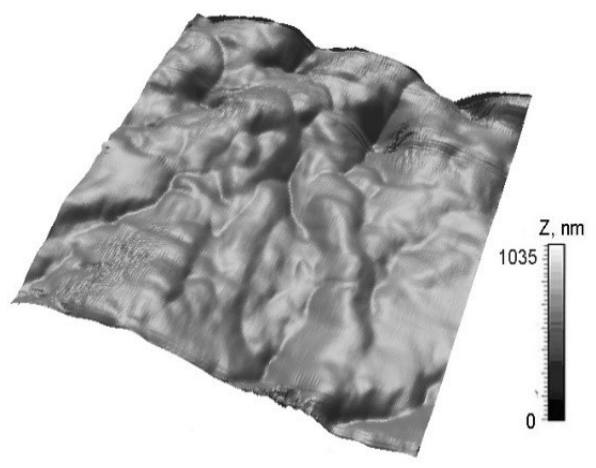

(b)

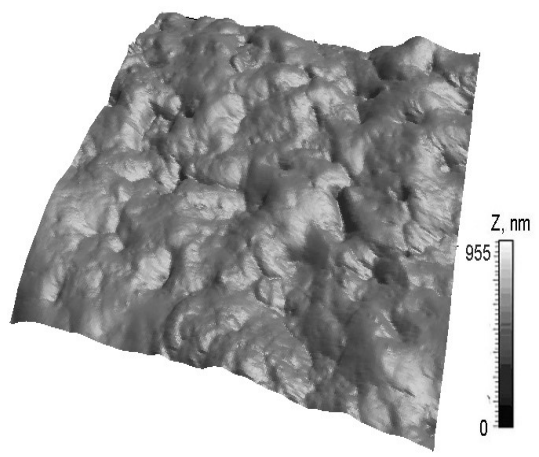

(c)

Figure 1. AFM images of rabbit cartilage surfaces $9 \times 9 \mu \mathrm{m}^{2}$ : (a) group 1; (b) group 2; and (c) group 3.

Damage and gaps were found on the cartilage tissue in group 2. Although the destruction sites were also found on cartilage in group 3, the size of the lesions decreased after PRP therapy. The roughness parameters of cartilage are presented in Figure 2.

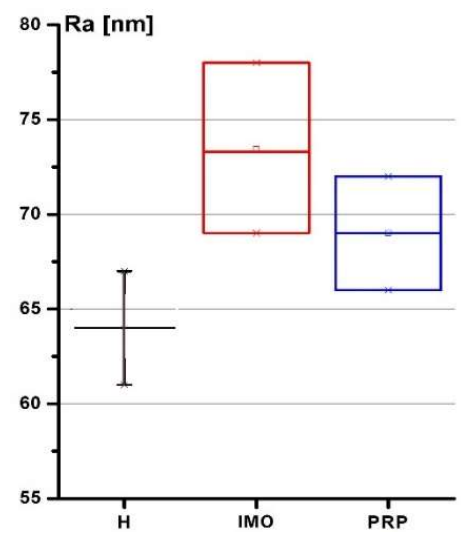

(a)

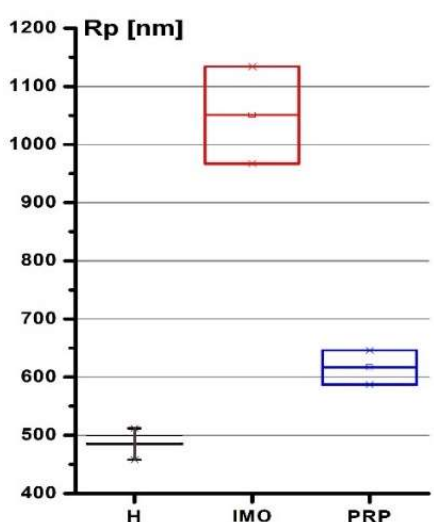

(b)

Figure 2. Cont. 


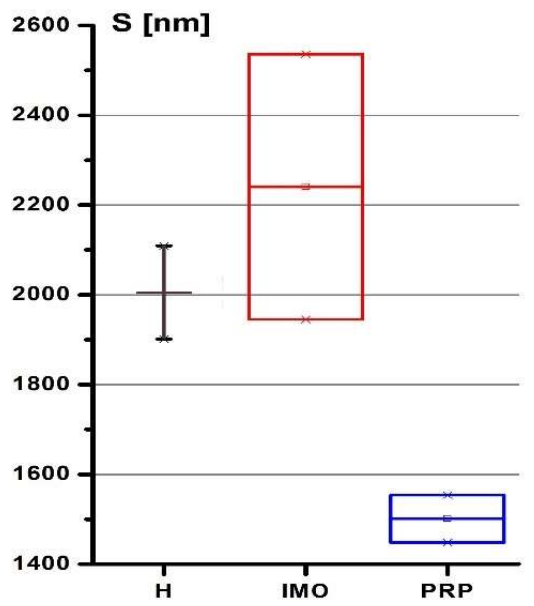

(c)

Figure 2. The roughness parameters in group $1(\mathrm{H})$, group 2 (IMO-induced model of osteoarthritis), and group 3 (PRP): (a) the arithmetic average of absolute values ( $\mathrm{Ra})$; (b) the maximum peak height (Rp); (c) the mean spacing between local peaks (S).

In group 2, the maximum of the arithmetic average of absolute values ( $\mathrm{Ra}$ ) change was a $25 \%$ increase; the maximum peak height (Rp) increased by $102 \%$, while the mean spacing between local peaks (S) increased by $28 \%$, compared to the control group $(p<0.05)$. Thus, the wear caused by artificial osteoarthritis differs from the submicron surface morphology that appears during the natural genesis and course of osteoarthritis which was described in [44]. This type of wear can be explained by mechanical damage caused by injections of surgical talc and the short duration of illness. In group 3 , Ra increased by $14 \%$; Rp increased by $32 \%$, while S decreased by $75 \%$, compared to the control group $(p<0.05)$. The same values amounted to an Ra decrease of $10 \%$, Rp decrease of $41 \%$, and S decrease of $40 \%$, compared to group $2(p<0.05)$. We found that the restoration of the surface morphology as a result of therapy was recorded. This is because the altitude parameters decreased below the initial value, as did the mean spacing between local peaks, which can be regarded as an increase in the density of small surface irregularities and the smoothing out of large ones. Our study revealed a significant decrease in the Young's modulus of the articular cartilage associated with OA disease. The corresponding indentation depth was 25-150 nm (Table 1).

Table 1. The Young's modulus from the indentation depth.

\begin{tabular}{cccc}
\hline $\boldsymbol{h}, \mathbf{n m}$ & Group 1, MPa (std) & Group 2, MPa (std) & Group 3, MPa (std) \\
\hline 25 & $1.95(0.035)$ & $1.60(0.027)^{*}$ & $1.71(0.022)^{*}$ \\
\hline 50 & $1.88(0.046)$ & $1.53(0.047)^{*}$ & $1.62(0.038)^{*}$ \\
\hline 75 & $1.37(0.046)$ & $1.40(0.050)^{*}$ & $1.50(0.070)^{*}$ \\
\hline 100 & $0.94(0.020)$ & $1.04(0.183)^{* *}$ & $1.22(0.075)^{* *}$ \\
\hline 125 & $0.75(0.035)$ & $0.79(0.131)^{* *}$ & $0.87(0.029)^{* *}$ \\
\hline 150 & $0.64(0.029)$ & $0.70(0.082)^{* *}$ & $0.71(0.024)^{* *}$ \\
\hline & &
\end{tabular}

The results have shown that the Young's modulus of a healthy joint cartilage ranges from $1.95 \mathrm{MPa}$ on the surface to $0.64 \mathrm{MPa}$ at a depth of $150 \mathrm{~nm}$. The range of the Young's modulus of the rabbits' cartilage in group 2 was from 1.60 to $0.70 \mathrm{MPa}$; the range of the Young's modulus in group 3 was from 1.71 to $0.71 \mathrm{MPa}$. Thus, it was found that the mechanical properties of hyaline cartilage deteriorate under the influence of simulated osteoarthritis; the Young's modulus of the surface layers decreased 
by $18 \%$ as a result of IMO $(p<0.05)$, and it increased by $9 \%(p<0.05)$ as a result of PRP therapy, which means that the mechanical properties of cartilage were partially recovered.

\section{Discussion}

Although animal models do not reflect all aspects of human pathology, they are still used in preclinical trials $[12,14,23,45,46]$. They play a significant role in understanding OA and the effects of therapeutic interventions. An induced model causing the initial stages of primary osteoarthritis in rabbits was used in this study. There are some differences between human and rabbit. Human weight-bearing is primarily locked on the knee extension, while rabbit hind limbs are usually kept in a fully flexed position [46]. Additionally, the cell densities are 1800 and 7500 per mm in humans and rabbits, respectively. Moreover, rabbit stifle joints have different load characteristics and cartilage thickness compared to humans [46]. Despite those differences, rabbits provide many advantages as they are easy to handle and to house and are cost-effective. Additionally, the rabbit model is the most adequate for this study because it is suitable for the assessment of cartilage repair; rabbits have large enough joints and appropriate size for simple surgical procedures and handling of specimens with a cartilage thickness of $0.25-0.75 \mathrm{~mm}$ [47]. The bone mineral density $\left(1.19 \mathrm{~g} / \mathrm{cm}^{3}\right)$ is similar to humans at the bone plate $\left(1.17 \mathrm{~g} / \mathrm{cm}^{3}\right)$ [23]. Rabbits were used for the assessment of cartilage repair in studies lasting up to 16 weeks $[48,49]$, and animal models of OA in which articular cartilage damage was induced with intra-articular collagenase injection have proved to be similar to human OA [50].

There is a significant gap regarding PRP clinical efficiency. Development of new methods and quantification of the PRP protocols are still under discussion. There are studies in the literature that tested the effect of PRP when used to treat OA in a rabbit model. In [51,52], the authors proved that PRP injection is regenerative in the collagenase-induced knee OA. The PRP treatment group demonstrated a greater extent of cartilage regeneration, as well as higher production of glycosaminoglycans in the extracellular matrix. In [53], the authors reported that the PRP-treated rabbits had the progression of osteoarthritis significantly decreased. Serra et al. [54] also used a rabbit model analyzing the effects of PRP on full-thickness articular cartilage defects. They found that the control group was both microscopically and macroscopically superior concerning defect filling, whereas the PRP group did not show better results compared with the placebo. Our study reveals that the difference of histologic scores between the non-treated group and PRP injected knees in group 3 was higher than those in group 2, which suggests that PRP injection is regenerative. In another research study, the OA changes were induced by different doses of $0.5-2.0 \mathrm{mg}$ by the intra-articular injection of [24,51,55-57]. In our study, the dose was $0.5 \mathrm{mg}$ and frequency of PRP injection was determined as four doses at seven-day intervals. It is in agreement with [57], in which the authors stated that the therapeutic effects of plasma therapy are based on the release from platelets-flat, nuclear-free cells that circulate in the bloodstream with a lifespan of 7-10 days.

Radiography, currently the gold standard for OA imaging, and other image modalities have limitations in the area of providing information about the mechanical properties of cartilage altered by degenerative joint disease. The atomic force microscopy (AFM) was widely utilized in the detection of pathological and the biomechanical properties of biological target structures on microscopic scale conditions [58-64]. In our study, AFM was used to test the mechanical properties and the submicron surface morphology of rabbits' hyaline cartilage. Pronounced heterogeneity of the biological surfaces' topography renders the utilization of AFM method quite challenging. Thus, we proposed a measurement protocol for the AFM method to determine the nanomechanical properties of articular cartilage. We pre-selected the silicon probes with a single radius of the needle point using a scanning electron microscope $( \pm 1 \mathrm{~nm})$ and with cantilever constant $( \pm 0.01 \mathrm{~N} / \mathrm{m})$ by testing samples with the previously known Young's modulus ( $\mathrm{NaCl}$ crystal with $E=37 \mathrm{GPa}$ ) to reduce error. The AFM indentation mode can be realized in a few ways depending on the set controlled parameter. We used the set-point as a controlled parameter. The set-point corresponds to relative deflection of the probe cantilever in the static mode of indentation. AFM moves the sample step-by-step towards the 
probe in such way that set-point changes in the preset range with equal steps between the set-point values. Measured cantilever deflection is a function of set-point. The dependence of the cantilever deviation on the set-point parameter is established, based on the measurement results. The cantilever deflection can be directly converted into force if the mechanical properties of the cantilever are known. Chandran et al. [65] stated that the indentation depth of at least $0.6 \mu \mathrm{m}$ is required to obtain values of matrix elasticity. It was observed that each $60 \mu \mathrm{m}$ change in indenter location could result in a twentyfold variation of the measurement [66]. Our previous research carried out to $450 \mathrm{~nm}$ in depth [67] shows that the surface is more suitable to diagnose, so in this study, we measured the mechanical properties of cartilage surface to $150 \mathrm{~nm}$ in depth. However, the statistical significance of the results was observed below $100 \mathrm{~nm}$. Past studies of articular cartilage have assumed a wide range of Poisson's ratios [63,64]. In this study [67], the local Poisson's ratio was assumed to be 0.5 for articular cartilage based on previous experimental reports. The changes in articular cartilage structure result in deterioration of the mechanical strength [60]. The roughness parameters of hyaline cartilage surface: the absolute value (Ra), the maximum peak height (Rp), and the mean spacing between local peaks (S) were measured for three groups: control; induced model of osteoarthritis; and the group with PRP treatment. Our results show that PRP injection into the knee under the patella can improve the mechanical properties and the submicron surface morphology of rabbits' hyaline cartilage: Ra and Rp increased, while $\mathrm{S}$ decreased compared to healthy rabbits' cartilage $(p<0.05)$. Moreover, $\mathrm{Ra}, \mathrm{Rp}$, and $\mathrm{S}$ decreased compared to group 2. The extent of mechanical compliance can be expressed as Young's modulus, which describes the elastic properties of a material [61,62]. In our study, the indentation clearly revealed a decrease in the Young's modulus of the upper layers of hyaline cartilage (up to $100 \mathrm{~nm}$ ). It increased by $9 \%$ as a result of PRP therapy, which means that the mechanical properties of cartilage partially recovered. Usually, the treatment effects require monitoring at longer time period. Therefore, we speculate that $0.5 \mathrm{mg}$ PRP injection is sufficient to evaluate morphological changes with AFM shortly after PRP injection.

Although the roughness measurements are routine in the presented field, the novelty of our study lies in using surface nano-roughness and microhardness of subsurface layers in describing changes in articular cartilage properties during development of OA. These parameters can be treated as essential indicators of the pathologic progression of OA diseases. In addition, the elastic modulus determined by AFM indentation experiments, can be utilized as a progressive disease marker in preventing the development of OA.

To the best of the authors' knowledge, this is the first study to assess the response to treatment consisting of intra-articular PRP injection on the mechanical properties and the submicron surface morphology of hyaline cartilage. The limitations of this study included the sample size and lack of therapeutic effects of PRP in severe knee OA over a long time. In the future, we will consider using a liquid cell for AFM measurements, because it eliminates surface tension and makes it possible to perform measurements immediately after obtaining the specimens.

\section{Methods}

\subsection{Induced Rabbits Model of Osteoarthritis}

Eighteen rabbits (chinchilla) from the Faculty of Veterinary Medicine at Grodno State Agrarian University, aged five months and weighing from 2400 to $3500 \mathrm{~g}$, were included in the study. The rabbits were equally divided into three groups of six: control (group 1); injections of saline $(0.5 \mathrm{~mL})$ and $10 \%$ surgical talc (Talcum Pharmaceutical ${ }^{\circledR}$, Minsk, Belarus) were delivered into the right knee under the patella (group 2 and 3); and PRP was injected into the right knee (group 3). The inclusion criteria were good appetite and activity, a shiny even coat, a clean nose and eyes, a body temperature in the range 38.5-39.5 Celsius degrees, a relative humidity of $49 \pm 8 \%$, a heart rate ranging from 120 to $160 \mathrm{BPM}$, and a respiratory rate ranging from 50 to 60 movements per $120 \mathrm{~min}$. The exclusion criteria included lack of appetite, intestinal disease, inactivity, or suppressed behavior. Experiments on animals were 
performed in accordance with internationally accredited guidelines, and had been approved by the Ministry of Health of the Republic of Belarus (No. 3, 13 January 2017). The rabbits were anesthetized by intramuscular administration of $10 \mathrm{mg} / \mathrm{kg}$ of xylazine (Ksilanit ${ }^{\circledR}$, Saratov, Russia) and $50 \mathrm{mg} / \mathrm{kg}$ of ketamine (Ketamine ${ }^{\circledR}$, Moscow, Russia) which kept the animal sedated for a longer time with minimal pain. Xylazine coadministered with ketamine is a safe anesthetic adjunct to induce short periods of surgical anesthesia. In [40], it was proved that the combination of both xylazine and ketamine cause rabbits' muscle relaxation; rabbits have a smoother emergence from anesthesia.

\subsection{Platelet-Rich Plasma (PRP) Preparation}

For PRP preparation, $9.0 \mathrm{~mL}$ of venous blood were drawn from the marginal auricular vein of the rabbit's ear and mixed with $0.5 \mathrm{~mL}$ of $0.0775 \mathrm{~mol} / \mathrm{L}$ sodium citrate acting as an anticoagulant. The blood was centrifuged at $1200 \mathrm{rpm}(160 \mathrm{~g})$ for $20 \mathrm{~min}$ to separate the plasma containing platelets from red cells. The plasma was drawn from the top layer and centrifuged for an additional $15 \mathrm{~min}$ at $2000 \mathrm{rpm}$ $(450 \mathrm{~g})$ to separate the platelets at a temperature of +18 to +22 Celsius degrees. After centrifugation, 0.6-0.7 $\mathrm{mL}$ of PRP was drawn from a plasma layer rich in platelets using a syringe and an injection needle [39]. Six rabbits underwent platelet-rich plasma therapy (group 3), while the other six did not receive PRP treatment (group 2). $0.5 \mathrm{~mL}$ of PRP were injected into right knee, and the injection dose was repeated in seven-day intervals. Groups 2 and 3 were quarantined for 14 days. Then, group 2 was euthanized by $\mathrm{CO}$ inhalation, and group 3 started PRP therapy. The first PRP injection was performed directly after surgery.

\subsection{Histologic Parameters}

The rabbit's articular cartilage was harvested after euthanasia from the femoral condyles, yielding $\sim 5 \mathrm{~mm} \times 5 \mathrm{~mm}$ pieces, $\sim 2 \mathrm{~mm}$ thick. All samples were fixed in $10 \%$ neutral buffered formalin for at least $48 \mathrm{~h}$. For histopathological examination, tissue samples were washed with $10 \%$ phosphate buffered saline solution, dehydrated in alcohol, and embedded in paraffin wax [13]. The degree of cartilage degradation was assessed using the scoring system modified by Mankin et al. [44]. A pathologist evaluated the structural change of articular cartilage as histological evidence of cartilage degeneration.

\subsection{Measurement Protocol for AFM Mechanical Properties of Rabbits Cartilage}

Atomic force microscopy AFM NT-206 (CMicroTestMachines, Gomel, Belarus) was performed to test submicron surface morphology and to measure the mechanical properties of rabbits' cartilage specimens in the static scanning mode in air. A CSC 38 MikroMasch ${ }^{\circledR}$ silicon probe (MikroMasch, Watsonville, CA, USA) was used. The resulting tip radius was less than $35 \mathrm{~nm}$, whereas the total tip height was 12 to $18 \mu \mathrm{m}$. The full tip cone angle was 40 degrees, and the probe material was n-type silicon. A type A cantilever with resonance frequency ranged from 8 to $32 \mathrm{kHz}$ was used. The force constant was from 0.01 to $0.36 \mathrm{~N} / \mathrm{m}$; length $250 \pm 5 \mu \mathrm{m}$; width $32.5 \pm 3 \mu \mathrm{m}$; thickness $1.0 \pm 0.5 \mu \mathrm{m}$ [44]. The scanning results were assessed with a scan area of $\mathrm{Ar}=9 \times 9 \mu \mathrm{m}^{2}$. The SurfaceExplorer (CMicroTestMachines, ver 1.1.5, Gomel, Belarus) software and NanoImages (ver 6.128.15, Mikhail Ihnatouski, Grodno, Belarus) were used to both visualize the experimental data and measure the roughness parameters: the arithmetic average of absolute values (Ra); the maximum peak height (Rp); and the mean spacing between local peaks (S). The parameters were measured at five points of each specimens (15 specimens per rabbit; five measurements per specimen; 1350 measurements in total).

The equations for calculation of Young's modulus from cantilever deflection data was derived using a linear model of interacting cantilever spring and elastic surface in conditions for quasi-static equilibrium presented as equality of cantilever spring forces exerted and elastic surface response [67]:

$$
k \cdot Z_{\text {defl }}=P(h)
$$


where $k$ is stiffness of the cantilever, and $P(h)$ is normal load as a function of variable indentation depth. The penetration of the probe $h$ into articular cartilage is presented by Equation (2) and in Figure 3 [67]:

$$
h=Z_{p o s}-Z_{d e f l}
$$

where $h$ is the penetration of the probe into cartilage, $\left(Z_{\text {defl }}\right)$ is the bend of the console, and $\left(Z_{p o s}\right)$ is the displacement of the console along the vertical axis.

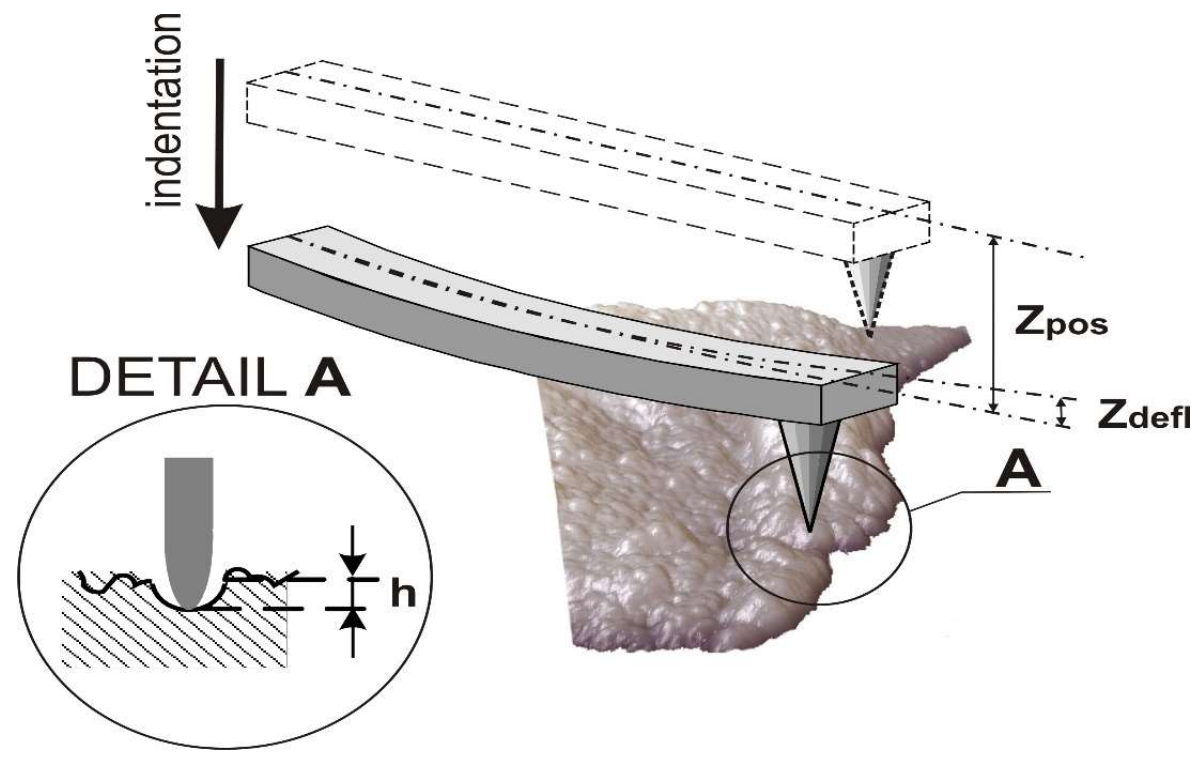

Figure 3. AFM indentation: $Z_{d e f l}$ the bend of the console; $Z_{p o s}$ the displacement of the console along the vertical axis; $h$-the penetration of the probe into cartilage.

The Young's modulus from the depth of penetration into the surface $(E(h))$ was investigated as follows:

$$
E(h)=\frac{3}{4}\left(1-v^{2}\right) \frac{k}{\sqrt{R}} \frac{z_{\text {defl }}}{h^{3 / 2}}
$$

where $v=0.5$ is the Poisson's ratio of the cartilage, $k=0.08 \mathrm{~N} / \mathrm{m}$ is the stiffness of the CSC 38 cantilever, and $R=30 \mathrm{~nm}$ is the radius of the needle point of the CSC 38 .

\subsection{Statistical Analysis}

Statistical analyses were performed using the Statistica software (StatSoft 13.1, Cracow, Poland). The data concerning the roughness parameters and Young's modulus were checked for normality using the Kolmogorov-Smirnov test. The Kruskal-Wallis test was used to compare the difference of the roughness parameters and Young's modulus among the three groups as well to compare the difference of histologic scores between non-treated and PRP-injected knees. A $p$-value $<0.05$ was considered as statistically significant. All data are presented as a mean \pm standard deviation (std).

\section{Conclusions}

The AFM method enables measuring the mechanical properties of hyaline cartilage during the disease process and after applied therapy in the short term. The results reflect the direction and magnitude of cartilage properties changes and show that PRP injection has positive effect on cartilage regeneration in the rabbit's knee. This research demonstrates that Young's modulus utilized on a nanometer scale has potential to be a progressive disease marker during the treatment of osteoarthritis. 
Author Contributions: Conceptualization: D.K.; project administration: M.I.; funding acquisition: M.I., J.P., and D.K.; methodology: M.I., J.P., D.K., and B.K.; data curation: D.K. and B.K.; software development: M.I.; validation: J.P.; formal analysis: M.I., J.P., and B.K.; writing—original draft: M.I. and J.P.; writing—review and editing: J.P. All authors have read and agreed to the published version of the manuscript.

Funding: This work was co-financed by the Ministry of Science and Higher Education of Poland within the framework of projects (WZ/WM-IIB/12/2019).

Conflicts of Interest: The authors declare no conflict of interest.

\section{References}

1. Murphy, L.B.; Schwartz, T.A.; Helmick, C.G.; Renner, J.B.; Tudor, G.; Koch, G.; Dragomir, A.; Kalsbeek, W.D.; Luta, G.; Jordan, J.M. Lifetime risk of symptomatic knee osteoarthritis. Arthritis Rheum. 2008, 59, 1207-1213. [CrossRef]

2. Leitch, K.M.; Birmingham, T.B.; Jones, I.C.; Giffin, J.R.; Jenkyn, T.R. In-shoe plantar pressure measurements for patients with knee osteoarthritis: Reliability and effects of lateral heel wedges. Gait Posture 2011, 34, 391-396. [CrossRef]

3. Ma, V.Y.; Chan, L.; Carruthers, K.J. Incidence, prevalence, costs, and impact on disability of common conditions requiring rehabilitation in the United States: Stroke, spinal cord injury, traumatic brain injury, multiple sclerosis, osteoarthritis, rheumatoid arthritis, limb loss, and back pain. Arch. Phys. Med. Rehabil. 2014, 95, 986-995.e1. [CrossRef]

4. Vos, T. Global, regional, and national incidence, prevalence, and years lived with disability for diseases and injuries, 1990-2015: A systematic analysis for the Global Burden of Disease Study 2015. Lancet 2016, 388, 1545-1602. [CrossRef]

5. Hootman, J.M.; Helmick, C.G.; Barbour, K.E.; Theis, K.A.; Boring, M.A. Updated Projected Prevalence of Self-Reported Doctor-Diagnosed Arthritis and Arthritis-Attributable Activity Limitation Among US Adults, 2015-2040. Arthritis Rheumatol. 2016, 68, 1582-1587. [CrossRef]

6. Duncan, R.; Peat, G.; Thomas, E.; Hay, E.; McCall, I.; Croft, P. Symptoms and radiographic osteoarthritis: Not as discordant as they are made out to be? Ann. Rheum. Dis. 2006, 66, 86-91. [CrossRef] [PubMed]

7. Neogi, T.; Zhang, Y. Epidemiology of osteoarthritis. Rheum. Dis. Clin. N. Am. 2012, 39, 1-19. [CrossRef] [PubMed]

8. Atkinson, M.H. Osteoarthrosis. Can. Fam. Physician Med. Fam. Can. 1984, 30, 1503-1507.

9. Danalache, M.; Tiwari, A.; Sigwart, V.; Hofmann, U.K. Application of Atomic Force Microscopy to Detect Early Osteoarthritis. J. Vis. Exp. 2020, 159, e61041. [CrossRef] [PubMed]

10. Roddy, E.; Choi, H.K. Epidemiology of gout. Rheum. Dis. Clin. N. Am. 2014, 40, 155-175. [CrossRef]

11. Van Zwieten, K.J.; Lambrichts, I.; Baker, B.; Kosten, L.; De Munter, S.; Gervois, P.; Schmidt, K.; Lippens, P. Some morphological substrates in the pathogenesis of arthritis, Conference: FlandersBio's Annual Life Sciences Convention Knowledge For Growth 2015. In Proceedings of the ICC, 11th Edition of Europe's Leading Regional Life Sciences Convention, Ghent, Belgium, 21 May 2015. [CrossRef]

12. Kuyinu, E.; Narayanan, G.; Nair, L.S.; Laurencin, C.T. Animal models of osteoarthritis: Classification, update, and measurement of outcomes. J. Orthop. Surg. Res. 2016, 11, 19. [CrossRef] [PubMed]

13. Aigner, T.; Cook, J.L.; Gerwin, N.; Glasson, S.; Laverty, S.; Little, C.; McIlwraith, C.; Kraus, V.B. Histopathology atlas of animal model systems-Overview of guiding principles. Osteoarthr. Cartil. 2010, 18, S2-S6. [CrossRef] [PubMed]

14. Takahashi, I.; Matsuzaki, T.; Hoso, M. Long-term histopathological developments in knee-joint components in a rat model of osteoarthritis induced by monosodium iodoacetate. J. Phys. Ther. Sci. 2017, 29, 590-597. [CrossRef] [PubMed]

15. Chouhan, D.K. The effect of intra-articular allogenic platelet rich plasma in Dunkin-Hartley guinea pig model of knee osteoarthritis. Muscle Ligaments Tendons J. 2017, 7, 426-434. [CrossRef]

16. Tsezou, A. Osteoarthritis Year in Review 2014: Genetics and genomics. Osteoarthr. Cartil. 2014, 22, $2017-2024$. [CrossRef]

17. Jones, I.A.; Togashi, R.; Wilson, M.L.; Heckmann, N.; Vangsness, C.T. Intra-articular treatment options for knee osteoarthritis. Nat. Rev. Rheumatol. 2018, 15, 77-90. [CrossRef] 
18. Wojtowicz, A. Comparison of efficiency of platelet rich plasma, hematopoietic stem cells and bone marrow in augmentation of mandibular bone defects. N.Y. State Dent J. 2007, 73, 41-45.

19. Gato-Calvo, L.; Magalhaes, J.; Ruiz-Romero, C.; Blanco, F.J.; Burguera, E.F. Platelet-rich plasma in osteoarthritis treatment: Review of current evidence. Ther. Adv. Chronic Dis. 2019, 10, 2040622319825567. [CrossRef]

20. Mehrabani, D.; Seghatchian, J.; Acker, J.P. Platelet rich plasma in treatment of musculoskeletal pathologies. Transfus. Apher. Sci. 2019, 58, 102675. [CrossRef]

21. Huang, Y.; Liu, X.; Xu, X.; Liu, J. Intra-articular injections of platelet-rich plasma, hyaluronic acid or corticosteroids for knee osteoarthritis. Der Orthopäde 2019, 48, 239-247. [CrossRef]

22. Sengul, A.T.; Buyukkkarabacak, Y.B.; Altunkaynak, B.Z.; Yetim, T.D.; Altun, G.Y.; Sengul, B.; Basoglu, A. Effects of platelet-rich plasma on cartilage regeneration after costal cartilage resection: A stereological and histopathological study. Acta Chir. Belg. 2016, 117, 21-28. [CrossRef] [PubMed]

23. Moran, C.J.; Ramesh, A.; Brama, P.A.J.; O’Byrne, J.M.; O’Brien, F.J.; Levingstone, T.J. The benefits and limitations of animal models for translational research in cartilage repair. J. Exp. Orthop. 2016, 3, 1-12. [CrossRef] [PubMed]

24. Dhillon, M.S.; Patel, S.; John, R. PRP in OA knee-Update, current confusions and future options. SICOT-J. 2017, 3, 27. [CrossRef] [PubMed]

25. Fioravanti, C.; Frustaci, I.; Armellin, E.; Condò, R.; Arcuri, C.; Cerroni, L. Autologous blood preparations rich in platelets, fibrin and growth factors. Oral Implant. 2016, 8, 96-113.

26. Moraes, V.Y.; Lenza, M.; Tamaoki, M.J. Platelet-rich therapies for musculoskeletal soft tissue injuries. Cochrane Database Syst. Rev. 2014, 4, CD010071. [CrossRef] [PubMed]

27. Sadabad, H.N.; Behzadifar, M.; Arasteh, F.; Behzadifar, M.; Dehghan, H. Efficacy of Platelet-Rich Plasma versus Hyaluronic Acid for treatment of Knee Osteoarthritis: A systematic review and meta-analysis. Electron. Physician 2016, 8, 2115-2122. [CrossRef] [PubMed]

28. Khoshbin, A.; Leroux, T.; Wasserstein, D.; Marks, P.; Theodoropoulos, J.; Ogilvie-Harris, D.; Gandhi, R.; Takhar, K.; Lum, G.; Chahal, J. The Efficacy of Platelet-Rich Plasma in the Treatment of Symptomatic Knee Osteoarthritis: A Systematic Review With Quantitative Synthesis. Arthrosc. J. Arthrosc. Relat. Surg. 2013, 29, 2037-2048. [CrossRef]

29. Amiel, D.; Toyoguchi, T.; Kobayashi, K.; Bowden, K.; Amiel, M.E.; Healey, R.M. Long-term effect of sodium hyaluronate (Hyalgan) on osteoarthritis progression in a rabbit model. Osteoarthr. Cartil. 2003, 11, 636-643. [CrossRef]

30. Schmidt, M.; Chen, E.; Lynch, S. A review of the effects of insulin-like growth factor and platelet derived growth factor on in vivo cartilage healing and repair. Osteoarthr. Cartil. 2006, 14, 403-412. [CrossRef]

31. Song, S.U.; Hong, Y.-J.; Oh, I.-S.; Yi, Y.; Choi, K.B.; Lee, J.W.; Park, K.-W.; Han, J.-U.; Suh, J.-K.; Lee, K.H. Regeneration of Hyaline Articular Cartilage with Irradiated Transforming Growth Factor $\beta 1$-Producing Fibroblasts. Tissue Eng. 2004, 10, 665-672. [CrossRef]

32. Wang, Q.; Yang, Y.Y.; Niu, H.J.; Zhang, W.J.; Feng, Q.J.; Che, W.F. Access An ultrasound study of altered hydration behaviour of proteoglycan-degraded articular cartilage. BMC Musculoskelet. Disord. 2013, $14,8$. [CrossRef] [PubMed]

33. Pauk, J.; Wasilewska, A.; Ihnatouski, M. Infrared Thermography Sensor for Disease Activity Detection in Rheumatoid Arthritis Patients. Sensors 2019, 19, 3444. [CrossRef] [PubMed]

34. Nieminen, M.T.; Casula, V.; Nevalainen, M.T.; Saarakkala, S. Osteoarthritis year in review 2018: Imaging. Osteoarthr. Cartil. 2019, 27, 401-411. [CrossRef] [PubMed]

35. Gahunia, H.K.; Lemaire, C.; Cross, A.R.; Babyn, P.; Kessler, M.J.; Pritzker, K.P.H. Osteoarthritis in Rhesus Macaques: Assessment of Cartilage Matrix Quality by Quantitative Magnetic Resonance Imaging. Jt. Destr. Arthritis Osteoarthr. 1993, 39, 255-259. [CrossRef]

36. Chizhik, S.A.; Arushko, A.V.; Wierzcholski, K. Structure and elastic properties of a cartilage at micro- and nanolevel. Russ. J. Biomech. 2008, 12, 13-22.

37. Wilusz, R.E.; DeFrate, L.E.; Guilak, F. Immunofluorescence-guided atomic force microscopy to measure the micromechanical properties of the pericellular matrix of porcine articular cartilage. J. R. Soc. Interface 2012, 9, 2997-3007. [CrossRef]

38. Krenev, L.; Volkov, S.S.; Sadyrin, E.V.; Zubar', T.I.; Chizhik, S.A. Mechanical Material Tests by the Nanoindentation Method at Various Indenter and Specimen Temperatures. J. Eng. Phys. Thermophys. 2018, 91, 594-600. [CrossRef] 
39. Zubar, T.I.; Chizhik, S.A. Studying Nanotribological Properties of Functional Materials via Atomic Force Microscopy. J. Frict. Wear 2019, 40, 201-206. [CrossRef]

40. Kuznetsova, T.G.; Starodubtseva, M.; Yegorenkov, N.; Chizhik, S.A.; Zhdanov, R.I. Atomic force microscopy probing of cell elasticity. Micron 2007, 38, 824-833. [CrossRef]

41. Abetkovskaia, S.O.; Chizhik, S.A.; Rudnitsky, V.A.; Kren, A.P. Evaluation of viscoelastic properties of materials by nanoindentation. J. Frict. Wear 2010, 31, 180-183. [CrossRef]

42. Youssef, D.; El-Ghandoor, H.; Kandel, H.; El-Azab, J.; Elnaby, S.H. Estimation of Articular Cartilage Surface Roughness Using Gray-Level Co-Occurrence Matrix of Laser Speckle Image. Materials 2017, 10, 714. [CrossRef] [PubMed]

43. Li, M.; Dang, D.; Li, W.J.; Xi, N.; Wang, Y. Imaging and Force Recognition of Single Molecular Behaviors Using Atomic Force Microscopy. Sensors 2017, 17, 200. [CrossRef] [PubMed]

44. Mankin, H.J.; Dorfman, H.; Lippiello, L.; Zarins, A. Biochemical and Metabolic Abnormalities in Articular Cartilage from Osteo-Arthritic Human Hips. J. Bone Jt. Surg.-Am. Vol. 1971, 53, 523-537. [CrossRef]

45. Gregory, M.H.; Capito, N.; Kuroki, K.; Stoker, A.M.; Cook, J.L.; Sherman, S.L. A Review of Translational Animal Models for Knee Osteoarthritis. Arthritis 2012, 2012, 1-14. [CrossRef] [PubMed]

46. Madry, H.; Ochi, M.; Cucchiarini, M.; Pape, D.; Seil, R. Large animal models in experimental knee sports surgery: Focus on clinical translation. J. Exp. Orthop. 2015, 2, 9. [CrossRef]

47. Hunziker, E.B. Biologic repair of articular cartilage: Defect models in experimental animals and matrix requirements. Clin. Orthop. Relat. Res. 1999, 367, 135-146. [CrossRef]

48. Chevrier, A.; Kouao, A.S.M.; Picard, G.; Hurtig, M.B.; Buschmann, M.D. Interspecies comparison of subchondral bone properties important for cartilage repair. J. Orthop. Res. 2014, 33, 63-70. [CrossRef]

49. Levingstone, T.J.; Thompson, E.; Matsiko, A.; Schepens, A.; Gleeson, J.P.; O’Brien, F.J. Multi-layered collagen-based scaffolds for osteochondral defect repair in rabbits. Acta Biomater. 2016, 32, 149-160. [CrossRef]

50. Yoshimi, T.; Kikuchi, T.; Obara, T.; Yamaguchi, T.; Sakakibara, Y.; Itoh, H.; Iwata, H.; Miura, T. Effects of High-Molecular-Weight Sodium Hyaluronate on Experimental Osteoarthrosis Induced by the Resection of Rabbit Anterior Cruciate Ligament. Clin. Orthop. Relat. Res. 1994, 298, 296-304. [CrossRef]

51. Funayama, A.; Niki, Y.; Matsumoto, H.; Maeno, S.; Yatabe, T.; Morioka, H.; Yanagimoto, S.; Taguchi, T.; Tanaka, J.; Toyama, Y. Repair of full-thickness articular cartilage defects using injectable type II collagen gel embedded with cultured chondrocytes in a rabbit model. J. Orthop. Sci. 2008, 13, 225-232. [CrossRef]

52. Kwon, D.R.; Park, G.Y.; Lee, S.-U. The Effects of Intra-Articular Platelet-Rich Plasma Injection According to the Severity of Collagenase-Induced Knee Osteoarthritis in a Rabbit Model. Ann. Rehabil. Med. 2012, 36, 458-465. [CrossRef] [PubMed]

53. Saito, M.; Takahashi, K.A.; Arai, E.; Inoue, A.; Sakao, K.; Tonomura, H.; Honjo, K.; Nakagawa, S.; Inoue, H.; Tabata, Y.; et al. Intraarticular administration of platelet-rich plasma prevents osteoarthritis progression in the rabbit knee. Clin. Exp. Rheumatol. 2009, 27, 201-207. [PubMed]

54. Serra, C.I.; Soler, C.; Carrillo, J.M.; Sopena, J.J.; Redondo, J.I.; Cugat, R. Erratum to: Effect of autologous platelet-rich plasma on the repair of full-thickness articular defects in rabbits. Knee Surg. Sports Traumatol. Arthrosc. 2013, 22, 1710. [CrossRef]

55. Sun, Y.; Feng, Y.; Zhang, C.Q.; Chen, S.B.; Cheng, X.G. The regenerative effect of platelet-rich plasma on healing in large osteochondral defects. Int. Orthop. 2009, 34, 589-597. [CrossRef] [PubMed]

56. Dhurat, R.S.; Sukesh, M. Principles and Methods of Preparation of Platelet-Rich Plasma: A Review and Author's Perspective. J. Cutan. Aesthetic Surg. 2014, 7, 189-197. [CrossRef] [PubMed]

57. Marx, R.E. Platelet-rich plasma: Evidence to support its use. J. Oral Maxillofac. Surg. 2004, 62, 489-496. [CrossRef]

58. Kiio, T.M.; Park, S. Nano-scientific Application of Atomic Force Microscopy in Pathology: From Molecules to Tissues. Int. J. Med. Sci. 2020, 17, 844-858. [CrossRef]

59. Maver, U.; Velnar, T.; Gaberšček, M.; Planinšek, O.; Finšgar, M. Recent progressive use of atomic force microscopy in biomedical applications. TrAC Trends Anal. Chem. 2016, 80, 96-111. [CrossRef]

60. Jin, H.; Liang, Q.; Chen, T.; Wang, X. Resveratrol Protects Chondrocytes from Apoptosis via Altering the Ultrastructural and Biomechanical Properties: An AFM Study. PLoS ONE 2014, 9, e91611. [CrossRef]

61. Lu, P.; Takai, K.; Weaver, V.M.; Werb, Z. Extracellular Matrix Degradation and Remodeling in Development and Disease. Cold Spring Harb. Perspect. Biol. 2011, 3, a005058. [CrossRef] 
62. Guz, N.; Dokukin, M.; Kalaparthi, V.; Sokolov, I.Y. If Cell Mechanics Can Be Described by Elastic Modulus: Study of Different Models and Probes Used in Indentation Experiments. Biophys. J. 2014, 107, 564-575. [CrossRef] [PubMed]

63. Choi, J.B.; Youn, I.; Cao, L.; Leddy, H.A.; Gilchrist, C.L.; Setton, L.A.; Guilak, F. Zonal changes in the three-dimensional morphology of the chondron under compression: The relationship among cellular, pericellular, and extracellular deformation in articular cartilage. J. Biomech. 2007, 40, 2596-2603. [CrossRef] [PubMed]

64. Alexopoulos, L.G.; Williams, G.M.; Upton, M.L.; Setton, L.A.; Guilak, F. Osteoarthritic changes in the biphasic mechanical properties of the chondrocyte pericellular matrix in articular cartilage. J. Biomech. 2005, 38, 509-517. [CrossRef] [PubMed]

65. Chandran, P.L.; Dimitriadis, E.K.; Mertz, E.L.; Horkay, F. Microscale mapping of extracellular matrix elasticity of mouse joint cartilage: An approach to extracting bulk elasticity of soft matter with surface roughness. Soft Matter 2018, 14, 2879-2892. [CrossRef] [PubMed]

66. Moshtagh, P.R.; Pouran, B.; Korthagen, N.; Zadpoor, A.A.; Weinans, H. Guidelines for an optimized indentation protocol for measurement of cartilage stiffness: The effects of spatial variation and indentation parameters. J. Biomech. 2016, 49, 3602-3607. [CrossRef]

67. Ihnatouski, M.; Pauk, J.; Karev, D.; Karev, B. AFM-Based Method for Measurement of Normal and Osteoarthritic Human Articular Cartilage Surface Roughness. Materials 2020, 13, 2302. [CrossRef] [PubMed]

Sample Availability: Samples of the compounds are not available from the authors. 